\title{
PERANCANGAN DESAIN INTERIOR KAFE DENGAN KONSEP INDUSTRIAL
}

\author{
Sri Wahyuni Panjaitan ${ }^{1}$ \\ Program Studi Desain Interior, \\ Fakultas Seni dan Desain, Universitas Potensi Utama \\ 1yuniwandriani@gmail.com
}

\begin{abstract}
ABSTRAK
Saat ini kafe adalah sebuah tempat yang digunakan untuk tempat makan, bahkan juga untuk tempat sebagai hiburan sederhana seperti bersantai dan berkumpul. Setiap kafe harus mampu memberikan sebuah pengalaman interior ruang berdasarkan karakteristik kafe tersebut. Selain itu café juga dapat dijadikan sebagai bisnis kuliner di kota besar seluruh Indoensia. Salah satu perkembangan bisnis kuliner yaitu café di kota Medan sangat berkembang. Situasi ini dapat membuat makin bertambahnya para kompetitor produsen bisnis kafe. Semua kompetitor kafe selalu berlomba-lomba untuk mempresentasikan dari keunggulan masingmasing bisnis kafe. Para kompetitor kafe selalu berjuang mengambil interes dari para pelanggan dan dapat memberikan kepuasan kepada para pelanggan. Semua kompetitor kafe selalu mempunyai banyak program untuk pemasaran usaha kafe sehingga melangkah dengan maju dalam melawan para competitor bisnis kafe yang lain, menghasilkan serta memperbanyak konsumen, serta menjaga para konsumen. Program pemasaran yang dapat diterapkan para kompetitor kafe salah satunya adalah pelayanan pada lingkungan fisik. Maka dari itu akan dirancangan desain interior dengan konsep industrial. Desain interior ini akan diterapkan pada salah satu café yang ada di Jalan Merak Sikambing B, Kelurahan Medan Sunggal, Kota Medan.
\end{abstract}

Kata kunci : Kafe, desain interior

\section{ABSTRACT}

urrently a cafe is a place that is used as a place to eat, even as a place for simple entertainment such as relaxing and gathering. Every cafe must be able to provide an interior space experience based on the characteristics of the cafe. In addition, the café can also be used as a culinary business in big cities throughout Indonesia. One of the culinary business developments, namely cafes in the city of Medan is very developed. This situation can increase the number of competitors in the cafe business. All cafe competitors are always competing to present the advantages of each cafe business. Cafe competitors always struggle to take interest from customers and can provide satisfaction to customers. All cafe competitors always have many programs for cafe business marketing so that they move forward against other cafe business competitors, generate and multiply consumers, and keep consumers. One of the marketing programs that can be applied by cafe competitors is service to the physical environment. Therefore, the interior design will be designed with an industrial concept. This interior design will be applied to one of the cafes on Jalan Merak Sikambing B, Medan Sunggal Village, Medan City. 
Keywords: Cafe, interior design

\section{PENDAHULUAN}

Saat ini semakin banyak kebutuhan manusia yang harus dipenuhi, seperti kebutuhan pokok yaitu pangan, papan dan sandang, kebutuhan hiburan juga harus terpenuhi. Seiring dengan kemajuann zaman semakin pesat, dalam memenuhi kebutuhan manusia sehari-hari tidak terlepas dari kebutuhan hiburan sebagai kebutuhan utama. Pada masa trend saat ini, keseharian manusia dapat dipenuhi dengan berbagai kegiatans padat sehingga dapat mengakibatkan stress dan kelelahan. Maka dari itu, dibutuhkan suatu wadah yang berfungsi untuk menyenangkan diri bahkan dapat menghilangkan rasa jenuh dan rasa penat dari semua kegiatan sehari-hari[1].

Kafe adalah salah satu tempat yang berfungsi untuk bersantai sembari menikmati berbagai macam makanan serta minuman dan ditemani dengan alunan musik. Saat ini pertumbuhan kafe semakin bertambah dapat dijumpai di seluruh Indonesia. Di Indonesia pertumbuhan Kafé tidak memiliki sumber yang jelas mengenai kehadiran pertama kafe di Indonesia. Kehadiran café di berbagai kot-kota besar di Indonesia, contohnya adalah Medan, yang mempunyai sangat besar pengaruh terhadap hal untuk memikat para pelancong dari dalam negeri maupun luar negeri. Selain itu Kota Medan juga memiliki potensi letaknya yang sangat strategis yang hampir dekat dengan kota Aceh, sehingga membuat banyak warga Aceh yang berkunjung ke kota Medan untuk berlibur, bersantai dan juga merasakan suasana kota medan. Sekarang ini, masyarakat memandang Kafe tidak hanya dari makanan saja namun juga suasana yang disediakan oleh Kafe yang merupakan khas dari kafe itu sendiri. Kondisi ini dapat terlihat dari banyaknya kehadiran kafe-kafe baru yang menawarkan tema, konsep dan sarana serta konsep visual yang berbeda, seperti contoh cafe yang memiliki tema sedang populer saat ini di Indonesia yaitu Konsep Industrial

Di tahun 1950 gaya desain industrial yang pertama kali menyebar di Eropa karena banyak bangunan-bangunan bekas pabrik yang terbengkalai. Demi ketepatgunaan dan mengupayakan keadaan kondisi, dilaksanakanh penyesuain pada bangunan-bangunan bekas pabrik tersebut suntuk sebuah hunian. Seiring berjalannya waktu, penggunaan konsep industrial tidak hanya pada bangunan pabrik, namun menelusuri ke jenis properti lainnya. Sekarang Konsep Industrial banyak digunakan pada rumah pribadi, sampai bangunan komersial seperti kafe-kafe dan restoran. Konsep industrial banyak menggunakan warnawarna monokrom yang yang memberi kesan maskulin, pemakaian materialnya pun tidak sembarangan dan juga banyak menerapkan material daur ulang atau bahan industri seperti besi, kaca serta aluminium yang diolah sedemikian rupa agar bisa dijadikan elemen interior yang menarik. Konsep industrial memang memiliki penggemarnya sendiri[2].

Perancangan Desain Interior Kafe dengan Konsep Industrial yang berada di J1 Merak Sikambing B, Kelurahan Medan Sunggal, Kota Medan. Lokasi ini di pilih oleh pemilik karena memilki tempat yang cukup strategis terutama di daerah perkotaan. Owner Cafe bertujuan membangun kafe tersebut, agar pengunjung dapat nongkrong secara nyaman serta memberikan suasana konsep industrial.

Metode yang diterapkan pada perancangan ini yaitu metode wawancara secara langsung dan metode observasi yang berdasarkan pada pengetahuan yang telah dirasakan secara langsung. Alasannya secara metodologi bagi pengamatan dan penggunaan dapat memaksimalkan kesanggupan peneliti dari aspek perilaku tak sadar, perhatian, motif, 
kebiasaan, kepercayaan dan sebagainya yang dapat memungkinkan untuk melihat dan mencermati sendiri serta mendokumentasikan peristiwa pada kondisi yang berhubungan pada pengetahuan proporsional maupun pengetahuan secara langsung diperoleh dari berbagai data. Maka daripada itu, perancang secara langsung mengunjungi Kafe yang beralamat dijalan merak Sikambing Medan.

Metode wawancara membutuhkan tanya jawab dengan maksud tertentu yang dilakukan oleh dua pihak yaitu pewawancara (interviewer) dan pihak yang di wawancarai (interviewe). Tujuan dari wawancara yaitu untuk mengumpulkan data dan informasi mengenai objek, organisasi, perasaan, motivasi, tuntutan, kepedulian dan lain-lain. Metode wawancara digunakan untuk mengumpulkan data dengan detail yang dilakukakan secara formal dan non formal terhadap pemilik Kafe. Data yang diperoleh yakni data primer. Data primer didapatkan dengan observasi secara langsung di lapangan dan melakukan wawancara dengan beberapa orang narasumber dengan list pertanyaan yang dibutuhkan. Hasil data-data yang didapat kemudian akan diolah dan dianalisis untuk menemukan permasalahan dari Kafe tersebut.

\section{STUDI LITERATUR}

1. Nur Fahdilah, M. Rusdi Tanjung, Perancangan Desain Interior Cafe Coffee Dengan Tema Rustic Modern Street Art, Jurnal FSD Vol.1, No.1

Tema pada perancangan ini dapat dilihat dari segi desain cafe coffee citra yang digunakan yaitu desain yang memberikan image cafe coffee yang menerapkan tema rustic modern dengan paduan street art pada umumnya yaitu modern, clean, tenang, nyaman, serta comfortable, bahkan ditambah dengan desain yang berkesan rustic street sehingga setiap orang yang berkunjung dapat merasakan suasana yang berbeda pada cafe lainnya. Desain ruang secara garis besar menerapkan style rustic modern street art. Pemakaian warna pada cafe coffee tidak banyak menggunakan warna yang colorfull. Warna yang dipakai adalah abu-abu dominan rustic dengan perpaduan street untuk memberikan kesan alami dan modern. Tidak hanya memakai warna abu-abu, namun juga memakai warna pendukung seperti hitam, putih, corak kayu juga digunakan pada beberapa bagian di cafe coffee. Untuk menghadirkan kesan rustic modern juga menggunakan warna alami seperti warna coklat dan tanah. Hal itu berlaku untuk desain interior modern. Selain itu, ditambahkan juga warna hitam sebagai aksen untuk menjadi unsur penting berguna mendapatkan kesan kokoh bahkan kuat dan memperkokoh tampilan objek pada sebuah ruangan[3].

Warna yang kan dipakai adalah warna dasar berdasarkan konsep rustic itu sendiri yang lebih unggul memakai warna natural bahkan memberikan kesan kuat dan warna alami mendekati wujud bahan yang diterapkan seperti warna hitam yang digunakan pada pagar dan besi holo sehingga dapat mengahasilkan kesan rustic modern pada cafe bahkan memberikan kesan kokoh. Warna abu digunakan pada bagian dinding tanpa finishing sehingga menghadirkan kesan alami pada bagunan yang lebih natural sehingga tema rustic lebih menonjol. Warna putih digunakan untuk ambalan sofa serta kaki kursi sehingga dapat berkesan bersih serta nyaman. Warna hijau di gunakan di bagian dinding pada musollah sehingga menghasilkan kesan yang natural dan segar. Sedangkan warna coklat merupakan warna yang digunakan di material kayu.

2. Liem Adrian Lukito, dkk, Perancangan Interior Librarica (Cafe \& Bar) Di Semarang, Jurnal Intra Vol.3, No.2 
Semarang mempunyai banyak prospek yang bagus-bagus pada perancangan bisnis food and beverages. Perancangan desain Librarica (cafe \& bar) dirancang untuk memberika faasislitas kepada masyarakat Semarang yang memerlukan tempat untuk berkumpul, bersantai, dan berbisnis. Serta bisa digunakan membantu untuk meningkatkan minat baca pada masyarakat Kota Semarang yang sedikit. Dengan adanya rancangan ini dapat memberikan jawaban dari kebutuhan masyarakat Semarang untuk berkumpul, bersantai, serta berbisnis. Setiap ruang-ruangan yang ada dalam rancangan ini bertujuan untuk melengkapi kebutuhan masyarakat Semarang. Berdasarkan penerapan suasana pada perpustakaan, cafe \& bar ini sehingga dapat memiliki fungsi penunjang selain berkumpul, bersantai, , berbisnis, makan serta minum, dapat juga berfungsi sebagai tempat membaca buku bahkan mencari berbagai informasi melalui wadah yang telah disediakan. Dengan rancangan ini dapat diharapkan untuk memenuhi kebutuhan masyarakat Semarang untuk berkumpul, bersantai, serta berbisnis dan juga diharapkan bisa membantu untuk meningkatkan minat baca pada masyarakat Semarang yang sedikit [4].

3. Monika Susanto, Andereas Pandu Setiawan, Perancangan Interior Café Dessert dan Cake Shop di Surabaya, Jurnal Intra Vol.2, No.2

Tema pada Perancangan Interior Cafe Dessert dan Cake Shop di Kota Surabaya ini memiliki latar belakang dan tujuan utama rancangan cafe sebagai tempat untuk bersantai dan berkumpul dalam kurun waktu lama dan dapat menyantap minuman dan makanan yang tersedia pada cafe tersebut Pada umumnya pengunjung cafe mendapatkan banyak pelayanan yang baik tanpa beralih dari tempat. Pelayanan yang disediakan oleh cafe semakin lama tidak memiliki inovasi dan kurang berkesan bahkan sangat membosankan.

Zaman ke zaman semakin modern dan terus berkembang, dengan bukti banyaknya cafe yang memberikan penawaran desain yang unik dan menarik. Namun dengan adanya pelayanan cafe yang menyenangkan pengunjung, maka rancangan desain cafe tersebut tidak dapat dinikmati secara utuh dan tidak mendapatkan makna dari rancangan desain café tersebut. Berdasarkan latar belakang rancangan café ini memiliki tujuan untuk dapat menyalakan kembali tujuan café yang didukung dengan hadirnya aktivitas para konsumen yang memiliki bmanfaat dan dapat juga membangun suasana yang menyenangkan sehingga memberikan kesan hiburan bagi setiap individu pengunjung.

\section{PEMBAHASAN}

\section{a. Konsep Desain}

Ciri khas konsep industrial yaitu memiliki beberapa material kasar seperti baja balok dan logam sengaja di ekspos untuk menunjukan cirikhas dan menampilkan suasana yang berhubungan dengan industri. Konsep ini umumnya di desain fungsional dberdasarkan latar belakang konsep industria dan Teknik yang kuat serta dapat bergelut pada pemilihan material yang memberikan kesan apa adanya, seperti lantai beton dan batu bata ekspos. Material yang difinishing dapat menonjolkan bentuk serta tektur alami. Maka dari itu konsep industrial ini, Jika dilihat secara kategori umum, maka konsep Industrial ini bukanya hanya digunakan untuk hunian saja tetapi pada kafe-kafe maupun restoran sangat lah cocok karna memiliki suasana yang unik dan nyaman[5].

\section{Tampak awal Perancangan Desain Interior Kafe}




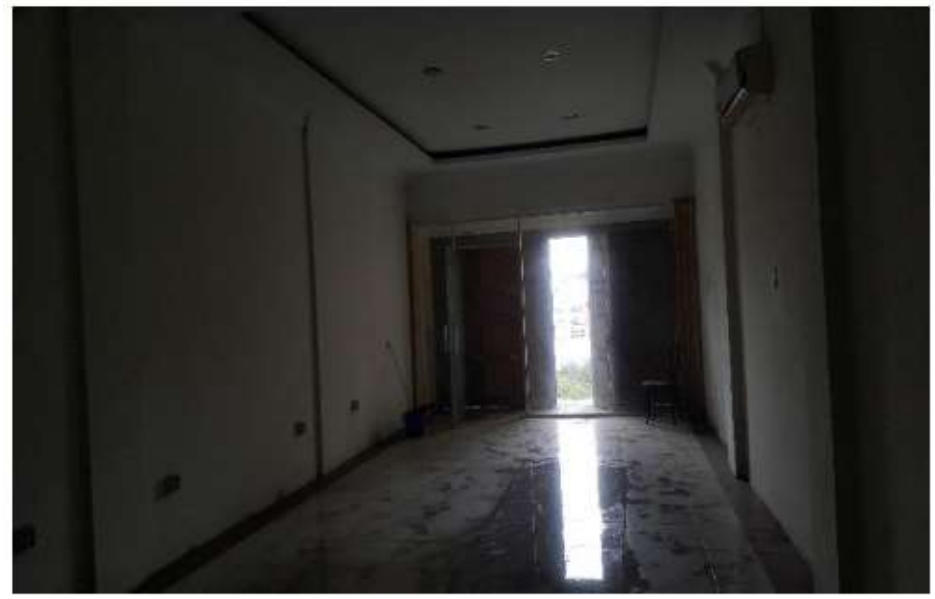

Gambar 1. Tampak Area Kafe Lantai 1

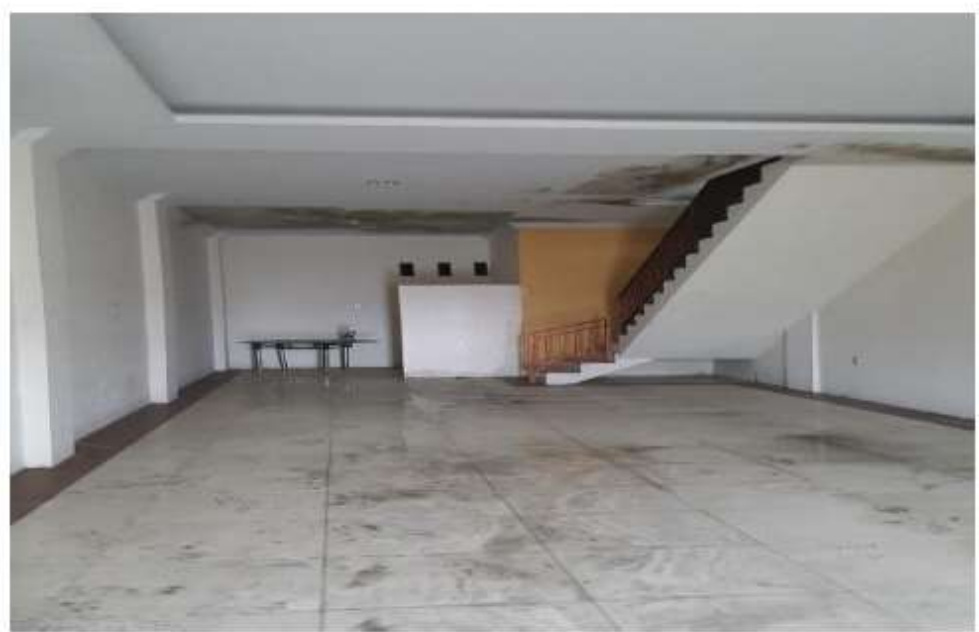

Gambar 2. Tampak Area Kafe Lantai 1 dan Resepsionist

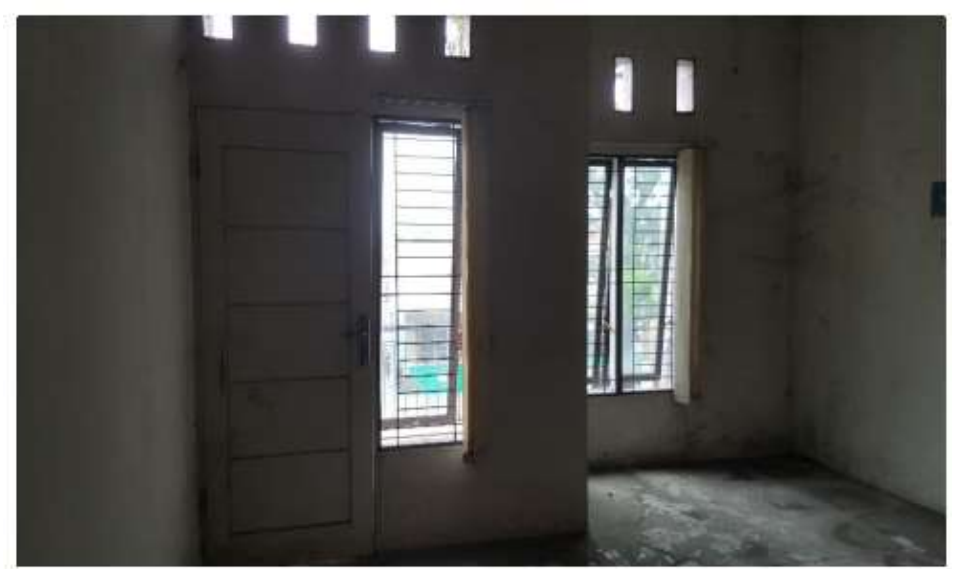

Gambar 3. Tampak Area Kafe Lantai 2 


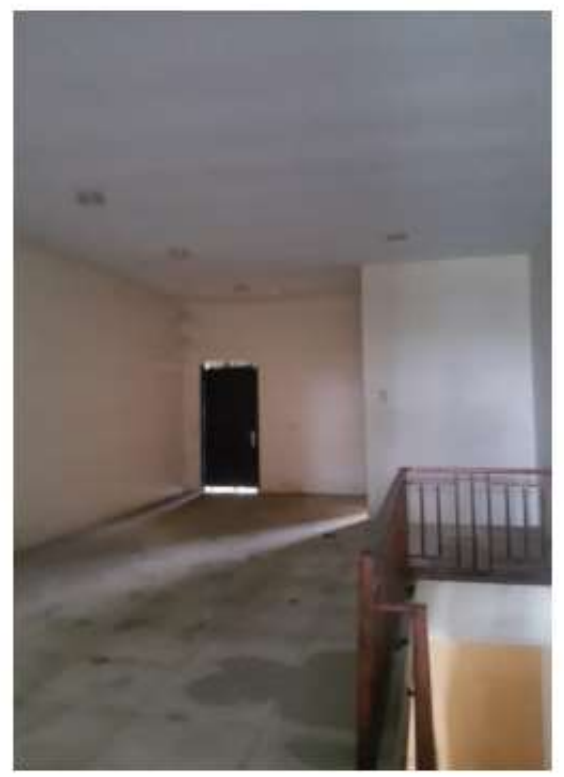

Gambar 4. Tampak Area Kafe Lantai 2 dan Resepsionist

1. Tampak Hasil Perancangan

a. Layout Denah

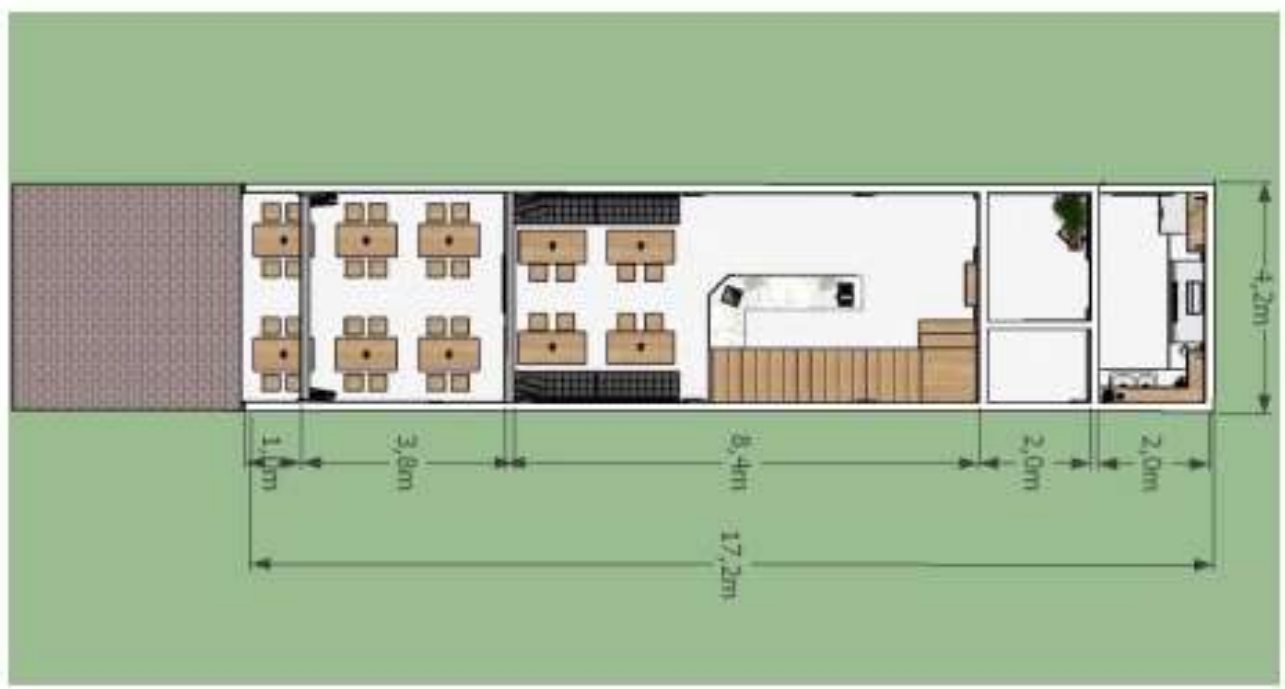

Gambar 5. Layout Denah Tampak Atas Lantai 1 
b. Prespektif

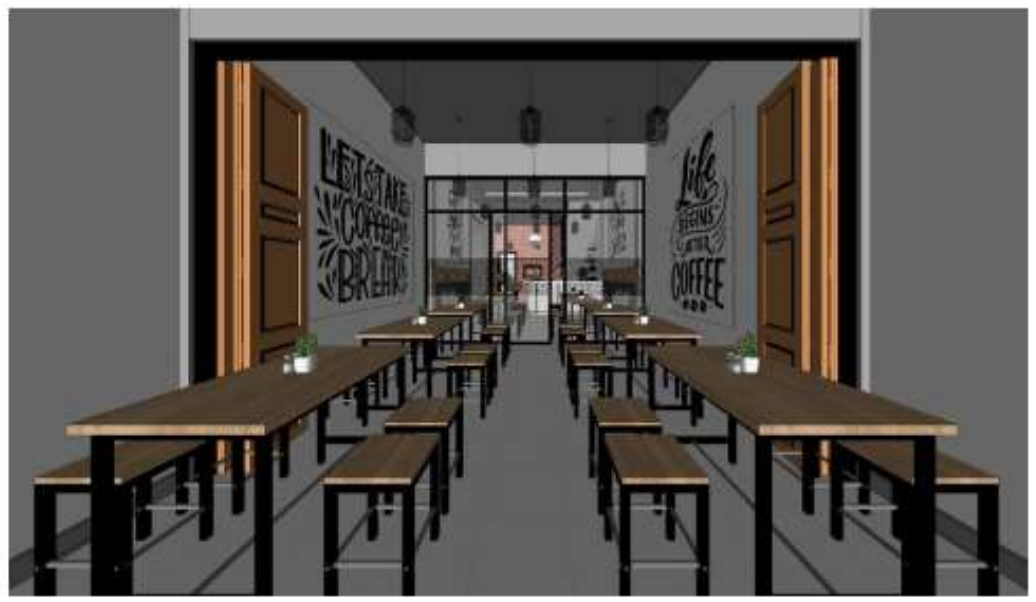

Gambar 6. Tampak Area Kafe Lantai I

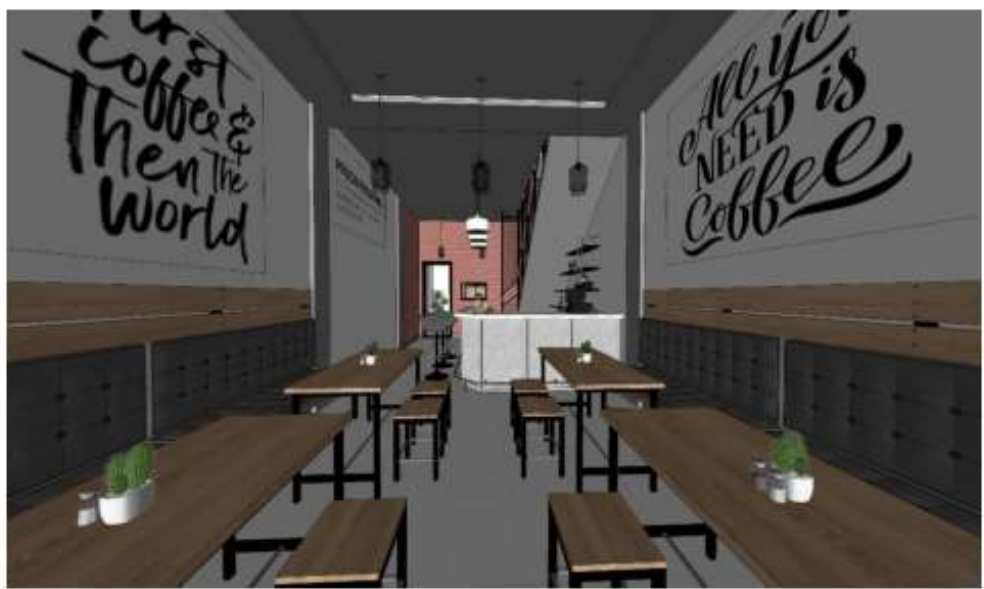

Gambar 7. Tampak Area Kafe Lantai I

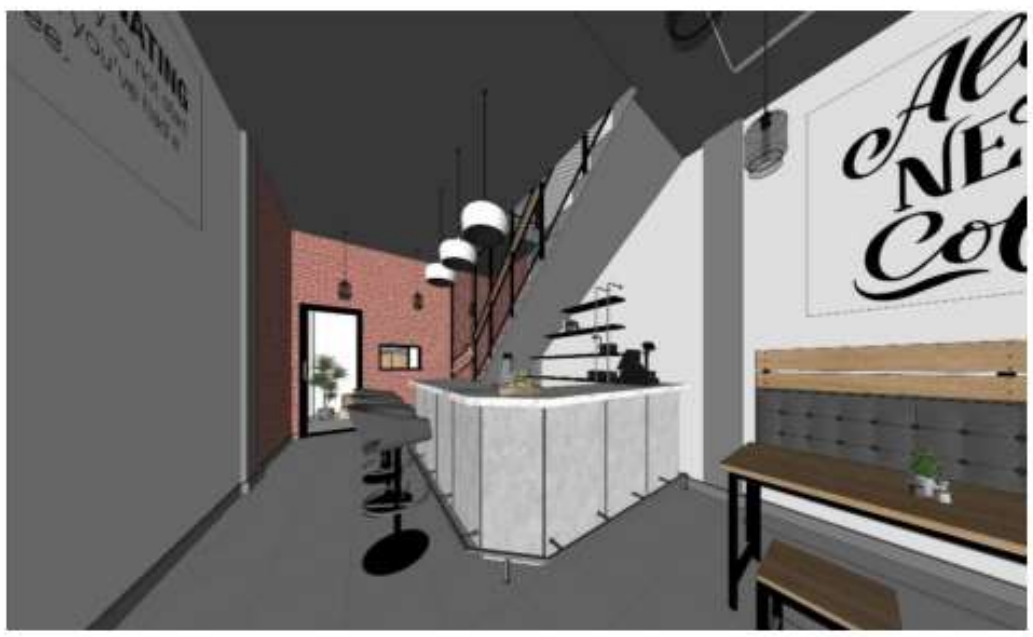

Gambar 8. Tampak Area Kafe Resepsionist lantai 1 


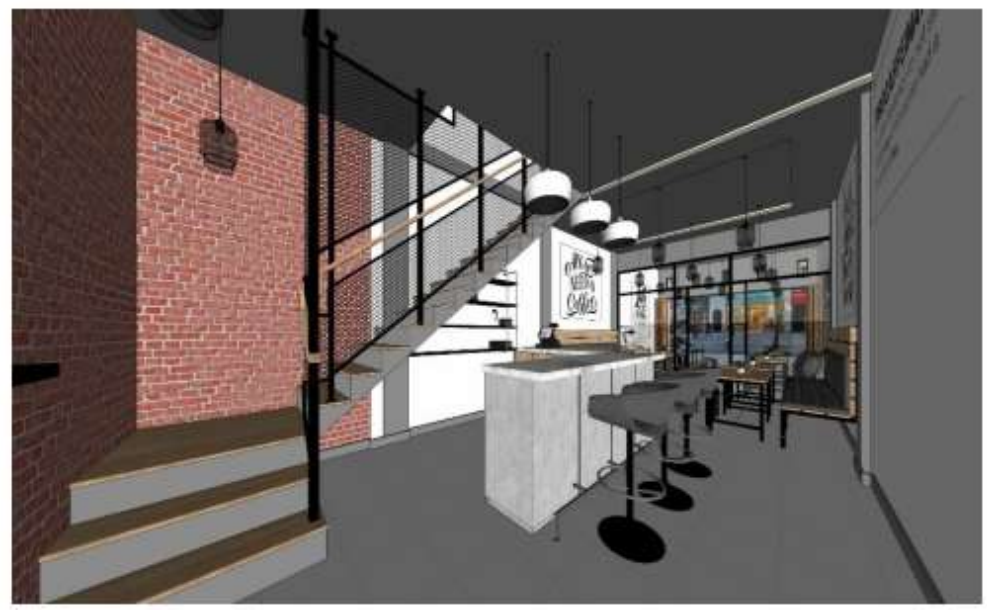

Gambar 9. Tampak Area Kafe Resepsionist lantai 1

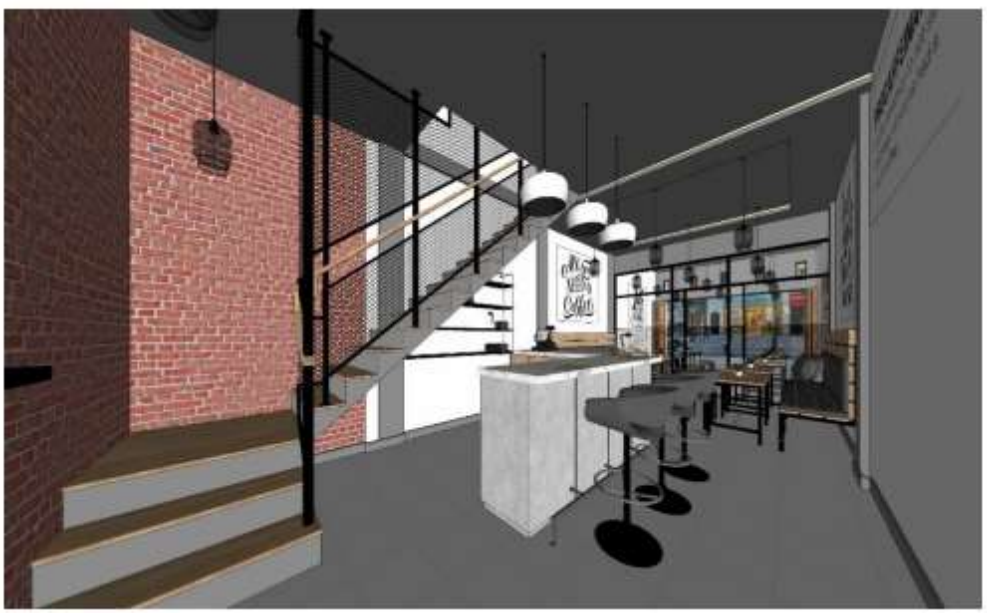

Gambar 10. Tampak Area Kafe Resepsionist lantai 1

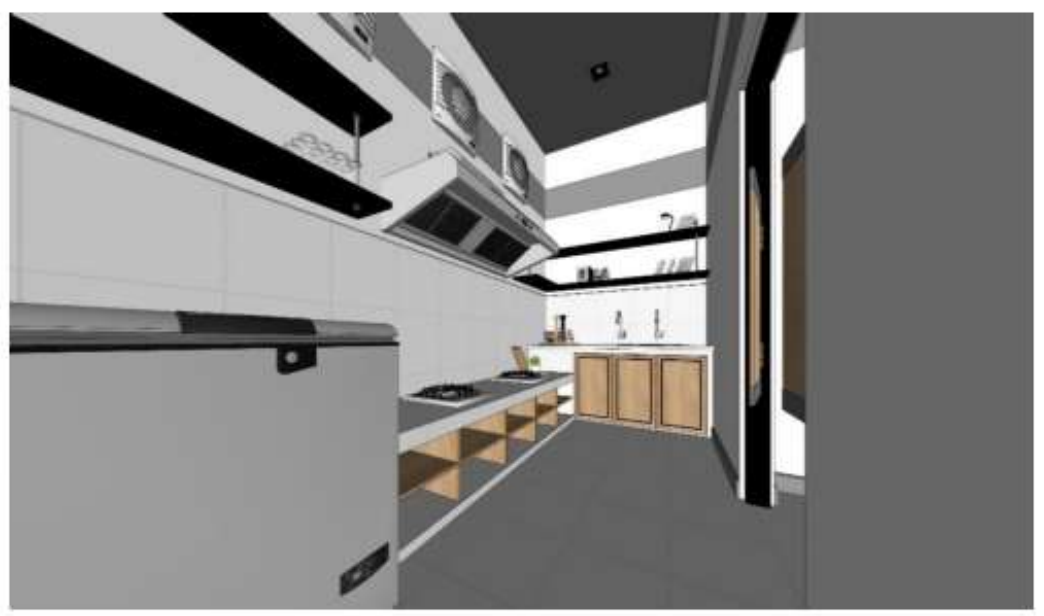

Gambar 11. Tampak Area Dapur Kafe 


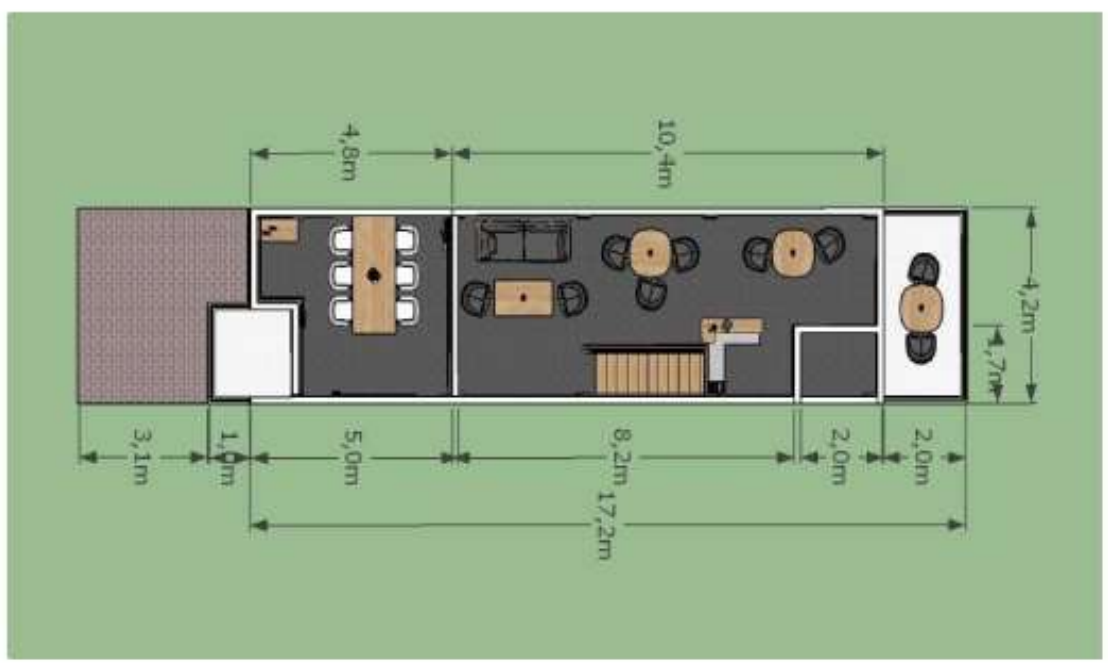

Gambar 12. Tampak Atas Denah Lantai 2

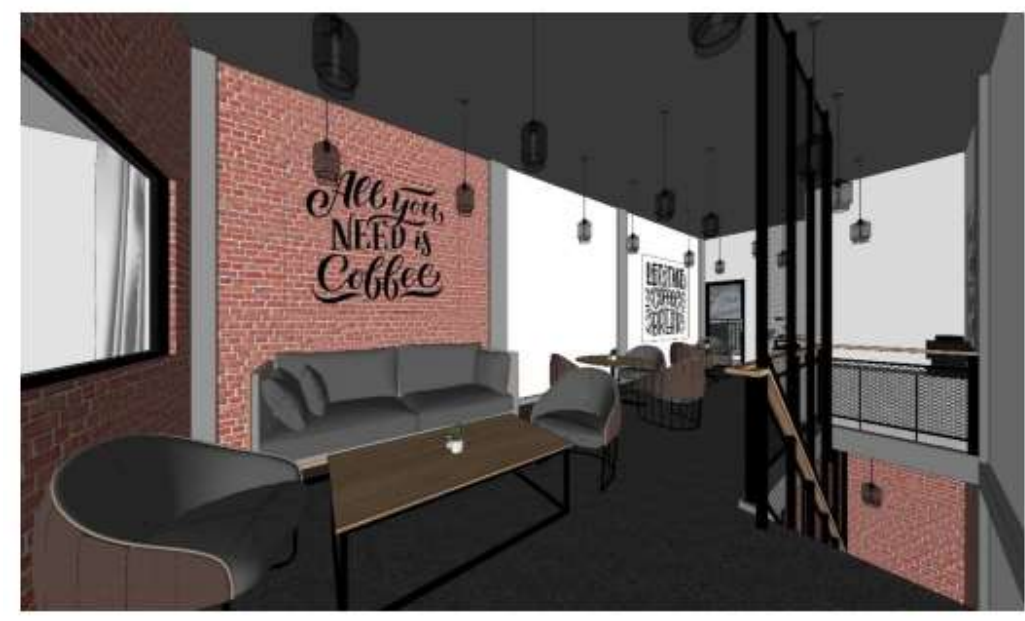

Gambar 13. Tampak Area Kafe Lantai 2

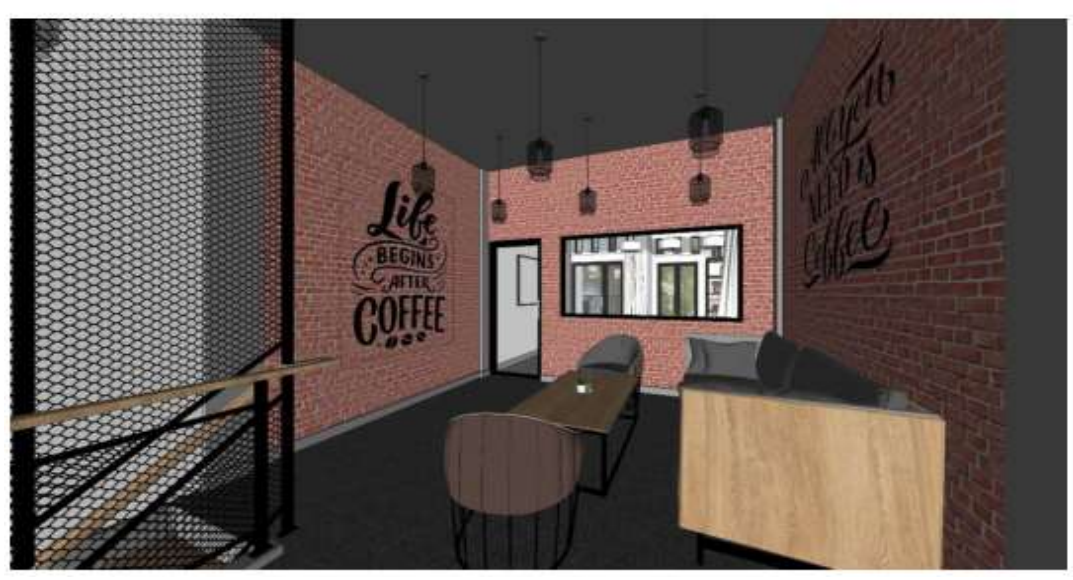

Gambar 14. Tampak Area Kafe Lantai 2 


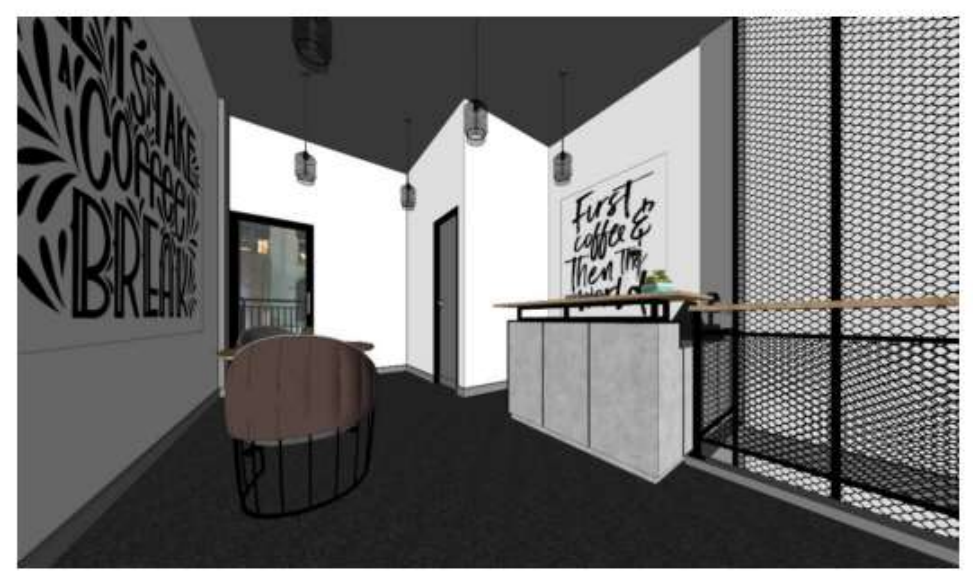

Gambar 15. Tampak Area Kafe Lantai 2

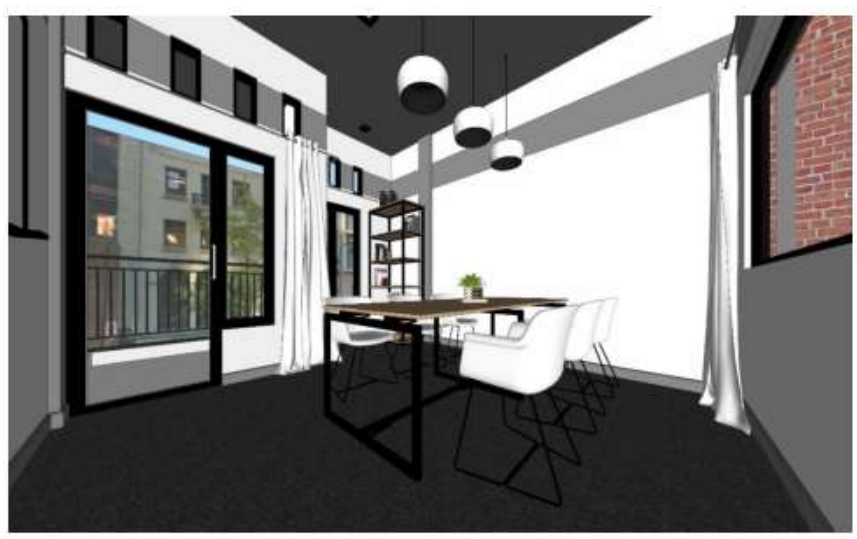

Gambar 16. Tampak Area Kafe Lantai 2

\section{KESIMPULAN}

Kota Medan memiliki banyak peluang yang sangat bagus dalam perancangan bisnis makanan dan minuman seperti kafe. Rancangan interior kafe ini didesain untuk memberikan fasilitas kepada masyarakat Medan yang memerlukan wadah untuk berkumpul, bersantai serta bersosialisasi. Pembaharuan rancangan interior ini bisa dilihat dari pengimplementasian tema industrial dengan fasilitas yang tersedia bagi pengunjung sehingga suasana dapat dinikmati dengan rileks oleh para pengunjung bahkan dapat melakukan aktivitas yang santai namun menyenangkan. 


\section{DAFTAR PUSTAKA}

\section{Tulisan/ artikel dalam buku:}

[1]. Y. H. Karjodihardjo and S. P. Honggowidjaja, "Perancangan Interior Library Cafe di Surabaya," Intra, vol. 3, no. 2, pp. 256-267, 2015, [Online]. Available: http://publication.petra.ac.id/index.php/desain-interior/article/view/3590.

[2]. M. S. A. P. Setiawan, "Perancangan Interior Café Dessert dan Cake Shop di Surabaya," Intra, vol. 2, no. 2, pp. 271-276, 2014.

[3]. N. Fahdilah, M. R. Tanjung, P. Studi, D. Interior, U. P. Utama, and R. Modern, "Perancangan Desain Interior Cafe Coffee Dengan Tema Rustic Modern Street Art," J. FSD, vol. 1, no. 1, pp. 38-51, 2019.

[4]. L. A. Lukito, L. K. Wardani, and L. Basuki, "Perancangan Interior Librarica (Cafe \& Bar) Di Semarang," J. Intra, vol. 3, no. 2, pp. 289-293, 2015.

[5]. J. Audrey, M. Wibowo, P. Studi, D. Interior, U. K. Petra, and J. Siwalankerto, "Perancangan Interior Café Thematic di Surabaya," INTRA, vol. 8, no. 1, pp. 24-29, 2020.

[6]. Shinsa, Kawade Shobo. Designer's Guide to Color. San Fransisco: Chronicle Books LLC, 2007.

[7]. Wijaya, Cindy Angga. Tugas Akhir: Perancangan Interior Kafe dan Toko Chocolate Corner di Surabaya. Surabaya: Fakultas Seni dan Desain Jurusan Desain Interior Universitas Kristen Petra, 2008.

[8]. Purwanto, Gabriel Indra. (2016). Perancangan Interior Coffee House di Surabaya Jurnal Intra, 4, (2). Retrieved 8 Januari, 2018.

[9]. Gunawan, Christine A. (2016). Perancangan Interior Kabinet Coffee di Surabaya Jurnal Intra, 4 (2). Retrieved 23 Desember, 2017

[10]. Karlen, mark, Benya James. 2007. Lighting Design Basics. Indiana University. Press. Aurigemma . 